\title{
MORFOLOGIA DA PLATAFORMA CONTINENTAL INTERNA ADJACENTE AO MUNICÍPIO DE TAMANDARÉ, SUL DE PERNAMBUCO - BRASIL
}

\author{
João Marcello Ribeiro de Camargo ${ }^{1}$, Tereza Cristina Medeiros de Araújo², \\ Mauro Maida ${ }^{3}$ e Thales Mitsuro Ushizima ${ }^{4}$ \\ Recebido em 27 setembro, 2005 / Aceito em 22 maio, 2007 \\ Received on September 27, 2005 / Accepted on May 22, 2007
}

\begin{abstract}
The study area is located off the southern coast of Pernambuco state, northeastern Brazil. The morphology of the inner continental shelf was investigated by means of twenty bathymetric profiles obtained with an echosounder GARMIN GPSMAP 185 Sounder. The surveyed area is an Environmental Protection Area (APA) called Coral Coast that is characterized by the occurrence of submerged beachrocks found at 16, 20 and $22 \mathrm{~m}$ depth, and a paleochannel with an N-S orientation. These morphological features are related with the coastal evolution of the southern Pernambuco continental shelf during Holocene sea-level variations and their description and location will be useful in future works concerning ancient conditions of sea-level stability. Mapping of submerged beachrocks contributes, as well, to the biodiversity conservation initiatives and the national and global coral reef monitoring programs.
\end{abstract}

Keywords: echosounding, submerged beachrocks, paleochannel, Pernambuco inner continental shelf.

RESUMO. 0 município de Tamandaré está localizado no litoral sul do Estado de Pernambuco, nordeste do Brasil. A morfologia da plataforma continental interna foi investigada com base em vinte perfis batimétricos obtidos por uma ecossonda GARMIN GPSMAP 185 Sounder. A área amostrada está inserida na Área de Proteção Ambiental (APA) Costa dos Corais e é caracterizada pela ocorrência de arenitos de praia submersos, distribuídos ao longo das isóbatas de 16, 20 e $22 \mathrm{~m}$ e pela presença de um paleocanal com uma orientação N-S. Estas feições morfológicas estão relacionadas com a evolução costeira da plataforma continental sul de Pernambuco durante variações do nível do mar. A localização e descrição dessas feições serão úteis em futuros trabalhos relacionados com condições pretéritas de estabilidade do nível do mar no Holoceno. Além disso, o mapeamento dos arenitos de praia submersos é um subsídio para iniciativas de conservação da biodiversidade e para os programas nacional e global de monitoramento de recifes de coral.

Palavras-chave: ecossondagem, arenitos de praia submersos, paleocanal, plataforma continental interna de Pernambuco.

\footnotetext{
1Laboratório de Oceanografia Geológica (LABOGEO) - UFPE, Avenida Arquitetura s/n, 50739-540 Recife, PE, Brasil. Tel.: (81) 2126-7225; Fax: (81) 2126-8225 -E-mail: jcamargocn@yahoo.com.br

2Laboratório de Oceanografia Geológica (LABOGEO) - UFPE, Avenida Arquitetura s/n, 50739-540 Recife, PE, Brasil. Tel.: (81) 2126-7225; Fax: (81) 2126-8225 - E-mail: tcma@ufpe.br

3 Projeto Recifes Costeiros, Rua Dr. Samuel Hardman s/n, 55578-000 Tamandaré, PE, Brasil. Tel./Fax: (81) 3676-2901 - E-mail: mauro.maida@ibama.gov.br

${ }^{4}$ Instituto Recifes Costeiros (IRCOS), Rua Dr. Samuel Hardman s/n, Centro, 55578-000 Tamandaré, PE, Brasil. Tel./Fax: (81) 3676-2901 - E-mail: dracena50@hotmail.com
} 


\section{INTRODUÇÃo}

0 município de Tamandaré está localizado a $110 \mathrm{~km}$ ao sul da cidade do Recife, capital do estado de Pernambuco. 0 litoral do município se estende entre as latitudes $8^{\circ} 42,602^{\prime} S$ e $8^{\circ} 46,671^{\prime}$ $S$ e apresenta formações recifais dispostas paralelamente à praia (Maida \& Ferreira, 1997) (Fig.1).

A plataforma continental do Estado de Pernambuco apresenta, na sua quase totalidade, reduzida largura (média de $35 \mathrm{~km}$ ), pouca profundidade, declive suave, quebra da plataforma entre -50 e -60 m, águas relativamente quentes, salinidade elevada e cobertura sedimentar composta por sedimentos terrígenos e carbonáticos biogênicos (Manso et al., 2003).

Uma feição morfológica característica do litoral pernambucano é sem dúvida a presença constante na plataforma continental interna de linhas de arenitos de praia, geralmente paralelas à costa, que servem como substrato para 0 desenvolvimento de algas e corais, além de constituir uma efetiva proteção à costa, na medida em que absorve grande parte da energia das ondas incidentes, mesmo estando os arenitos de praia completamente submersos (Manso et al., 2003). Em relação a tais arenitos de praia, geralmente ocorrem duas ou três exposições com a primeira quase sempre emersa e próxima à praia e as demais praticamente submersas ou parcialmente emersas, sendo todas relacionadas às antigas linhas de praia (Branner, 1904; Mabesoone,1964).

A área de estudo está inserida na Área de Proteção Ambiental (APA) Costa dos Corais, a maior Unidade de Conservação Marinha do Brasil. Durante os últimos anos, o Projeto Recifes Costeiros (UFPE-IBAMA-FMA-BID) desenvolveu pesquisas científicas na região, com 0 intuito de contribuir para a elaboração de um Plano de Manejo para a APA Costa dos Corais. 0 mapeamento dos recifes costeiros e seu monitoramento biológico foram algumas atividades desenvolvidas pelo citado projeto (César \& Padovani, 2004), visto que estas feições representam o principal atrativo natural da região.

A investigação da morfologia submarina de uma plataforma continental é capaz de revelar indícios acerca da evolução costeira, uma vez que geralmente a morfologia é relíquia de ambientes sedimentares relacionados com períodos de nível do mar mais baixo que 0 atual.

Desta forma, o presente trabalho descreve e investiga a morfologia da plataforma continental interna ao largo de Tamandaré e gera subsídios para iniciativas de conservação da biodiversidade marinha, para programas de monitoramento dos ecossistemas recifais (Reef Check Brasil) e para estudos sobre as variações do nível do mar, durante o Holoceno. Vale lembrar que o posicionamento dos arenitos de praia submersos é um conhecimento empírico compartilhado por pescadores artesanais, que não utilizam equipamentos de posicionamento (GPS, DGPS). Portanto, 0 presente trabalho também representa uma iniciativa de disponibilizar tal conhecimento à comunidade científica, que atua localmente em prol da conservação dos ecossistemas marinhos e do manejo pesqueiro.

\section{MATERIAL E MÉTODOS}

$\mathrm{Na}$ área de estudo, os métodos de mapeamento dos ambientes recifais através de imagens de satélite e fotografias aéreas obtiveram resultados apenas para os recifes situados próximos a superfície e que geralmente são expostos durante a baixa-mar (Lima, 2003). Todavia, os levantamentos batimétricos são uma alternativa viável para a localização de recifes submersos, pois estas feições geralmente apresentam um relevo superior a 2 metros e, portanto são detectáveis num perfil batimétrico (Vora \& Almeida, 1990).

Os dados analisados no presente trabalho foram obtidos a bordo do R/V Velella, pertencente ao Projeto Recifes Costeiros. Para os levantamentos foi utilizada uma ecossonda com sistema de posicionamento integrado GARMIN GPSMAP 185 Sounder, durante a execução de vinte perfis batimétricos, nos dias 09 de julho, 18 e 19 de novembro de 2004. Estes perfis foram realizados com uma distância de 500 m entre eles e com uma orientação sudeste-noroeste entre as profundidades de 7 e $32 \mathrm{~m}$ (Fig. 2). 0 presente levantamento foi realizado ao largo da última linha de arenito de praia parcialmente emersa e condições de navegação desfavoráveis impediram 0 deslocamento da embarcação sobre alguns recifes localizados na porção mais rasa da área amostrada, logo, algumas destas feições morfológicas foram registradas apenas parcialmente nos perfis batimétricos obtidos.

Os valores de profundidade foram corrigidos com base na Tábua de Marés para o Porto de Suape, calculada e publicada pela Diretoria de Hidrografia e Navegação (DHN, 2004). Um filtro passa-baixa descrito por Limeburner (1985) foi aplicado aos perfis batimétricos a fim de se eliminar as variações de alta freqüência decorrentes de instabilidades na embarcação frente à atuação das ondas. Usando o programa Surfer 8.0, 0 padrão de distribuição das isóbatas e uma visualização tridimensional do terreno foram obtidos após a interpolação do tipo "Natura/ Neighbor" dos dados de profundidade corrigida. 


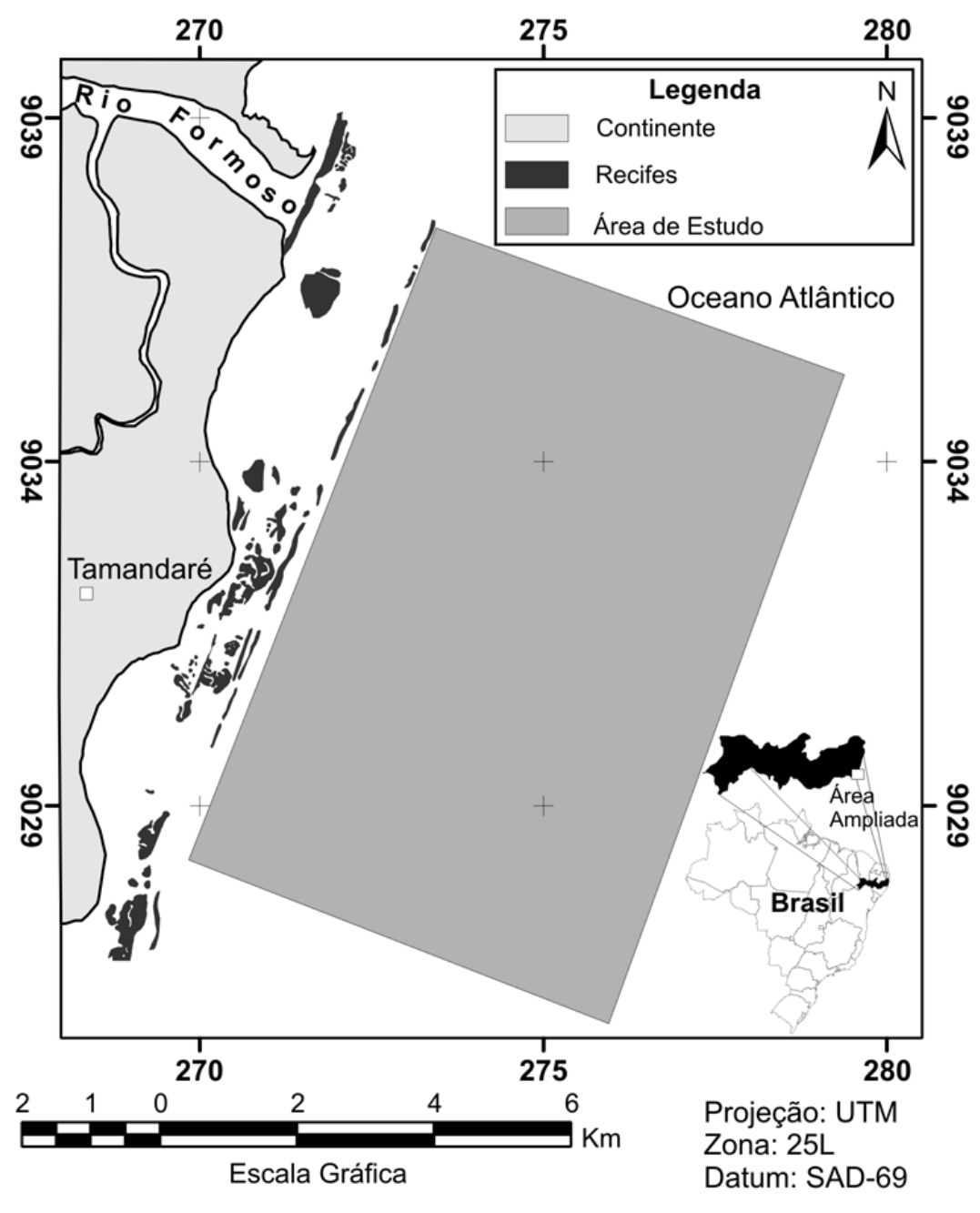

Figura 1 - Localização da área de estudo.

\section{RESULTADOS E DISCUSSÃO}

Os perfis batimétricos obtidos foram utilizados na descrição da morfologia da plataforma continental interna adjacente ao município de Tamandaré. As características morfológicas de cada perfil foram reunidas na Tabela 1, que indica as profundidades inicial, final, mínima e máxima de cada perfil, bem como seu comprimento e declividade (Tab. 1).

Os perfis apresentaram comprimentos entre $4.023,7 \mathrm{e}$ $6.198,1 \mathrm{~m}$ e foram registradas profundidades entre $-7,51 \mathrm{e}$ $-32,60 \mathrm{~m}$, sendo que as profundidades iniciais e finais de cada perfil variaram de acordo com as condições de navegação.

Já em relação à declividade dos perfis, esta variou entre 1:242 e 1:811, sendo os perfis $3,5,6$ e 7 aqueles com declividades mais acentuadas, enquanto que os perfis 12, 13, 19 e 20 aqueles com as declividades mais suaves. De modo geral, na porção mais ao norte da área de estudo os perfis apresentaram uma declividade mais suave em relação aos demais perfis (Fig. 3).

0 padrão de isóbatas e a variação espacial das profundidades na área de estudo evidenciaram a presença de relevos negativos representados pela porção mais profunda da área, configurada em um canal (Fig. 2).

A análise dos vinte perfis batimétricos obtidos permitiu observar suaves declives, intercalados por relevos positivos e negativos. Exemplos típicos são os perfis 2, 9, 12 e 15 (Fig. 4).

Em relação aos relevos positivos, estes foram registrados em 18 dos 20 perfis, em torno das profundidades de 16, 20 e $22 \mathrm{~m}$. Estas feições apresentaram morfologias distintas, no que diz respeito às suas larguras e alturas. No caso dos relevos positivos em torno dos $16 \mathrm{~m}$, suas larguras não puderam ser determinadas, já 


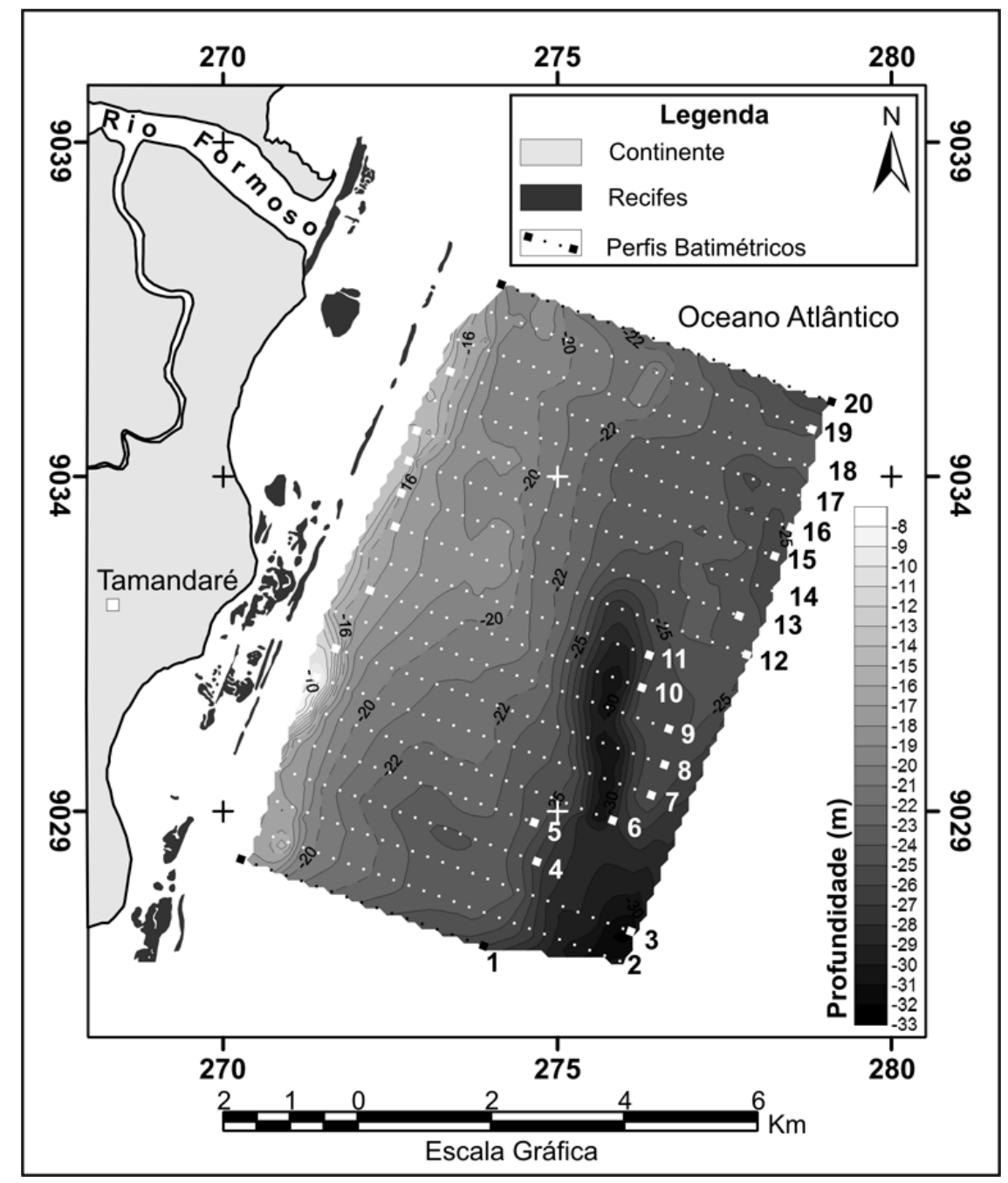

Figura 2 - Posicionamento dos perfis batimétricos e a distribuição espacial das profundidades.

que essas feições foram registradas apenas parcialmente (Tab. 2).

Os relevos positivos situados em torno da isóbata de $16 \mathrm{~m}$ foram registrados apenas parcialmente nos perfis $5,6,8,11,14$, 15, 16, 17 e 18 e apresentaram as maiores variações verticais, com desníveis entre 2,3 e 9,8 m e um valor médio de 5,6 m. Os relevos positivos situados em torno da isóbata de $20 \mathrm{~m}$ foram registrados integralmente nos perfis $1,2,3,4,7,11,12,13$, $14,15,17,18,19$ e 20 . De forma geral, suas alturas variaram entre 0,5 e 9,5 m, com um valor médio de 3,6 m, enquanto que suas larguras apresentaram valores entre 169,3 e $810 \mathrm{~m}$, com um valor médio de 445,9 m. Já aqueles situados em torno da isóbata de $22 \mathrm{~m}$ foram também registrados integralmente nos perfis 14 , 15,18 e 19. Suas alturas variaram entre 1,5 e 3,2 m, com um valor médio de 2,15 m. Enquanto que, suas larguras apresentaram valores entre 177,4 e 426,6 m, com um valor médio de 339,1 m. A Figura 5 ilustra a ocorrência destas feições morfológicas nas profundidades supracitadas.

Entre os perfis 5, 6 e 7 concentraram-se as maiores elevações situadas em torno das isóbatas de 16 e $20 \mathrm{~m}$ (Tab. 2). Este fato provavelmente deve-se a condições mais favoráveis, nesta porção da área de estudo, para a formação de feições positivas e/ou desfavoráveis à sua erosão, em relação aos demais perfis. Nesse sentido, futuros estudos relacionados aos processos de gênese e erosão das feições positivas poderão explicar a variação espacial de suas alturas.

A localização dos relevos positivos representa uma importante contribuição a futuros trabalhos relacionados com a evolução costeira, já que estas feições provavelmente estão associadas 


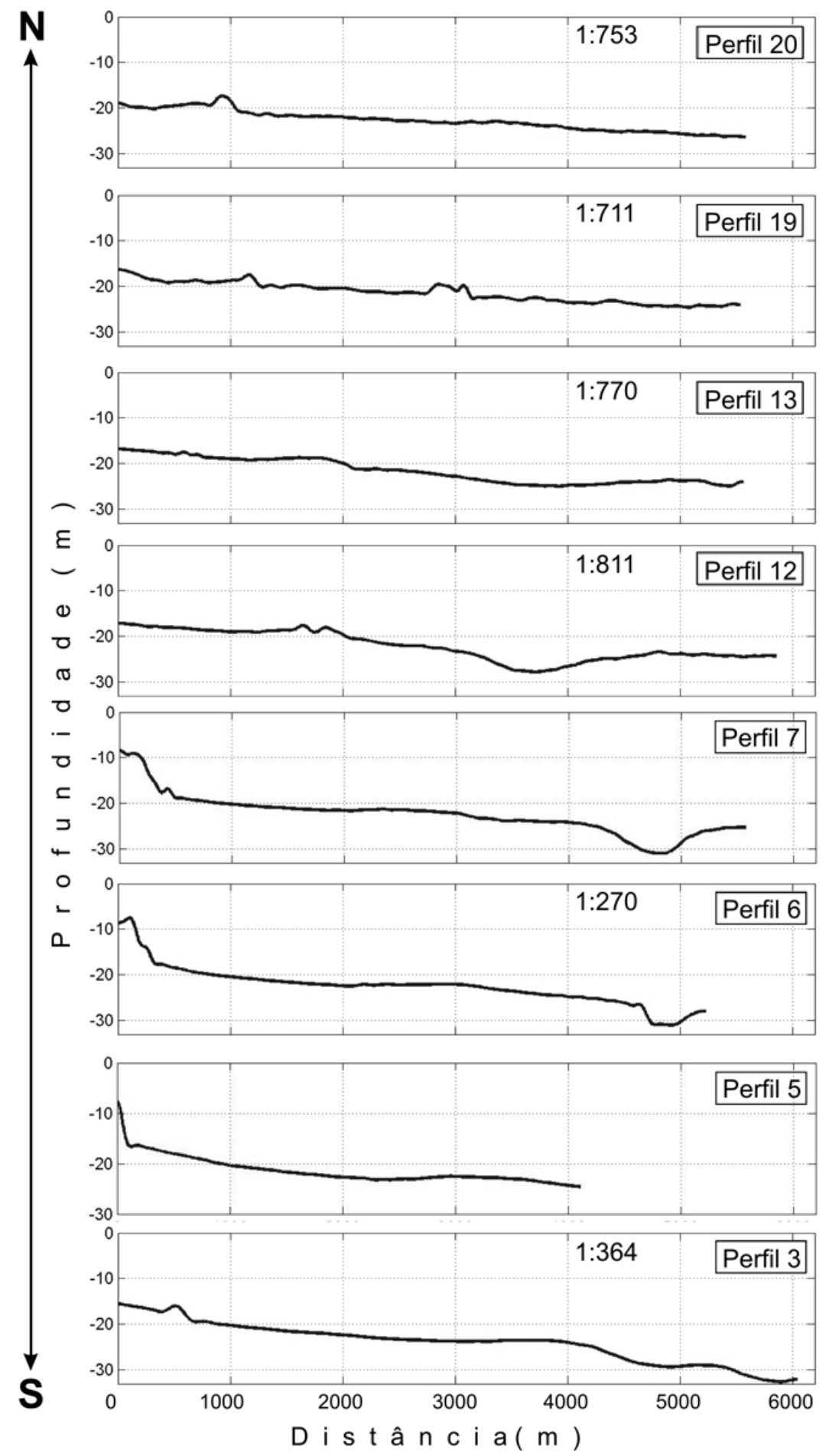

Figura 3 - Perfis batimétricos com as declividades mais acentuadas (área sul) e as declividades mais suaves (área norte). 
Tabela 1 - Profundidades inicial, final, mínima e máxima; comprimento e declividade de cada um dos perfis batimétricos levantados.

\begin{tabular}{|c|c|c|c|c|c|c|}
\hline Perfil & $\begin{array}{c}\text { Profundidade } \\
\text { inicial }(\mathrm{m})\end{array}$ & $\begin{array}{c}\text { Profundidade } \\
\text { final }(\mathrm{m})\end{array}$ & $\begin{array}{c}\text { Profundidade } \\
\text { mínima }(\mathrm{m})\end{array}$ & $\begin{array}{c}\text { Profundidade } \\
\text { máxima }(\mathrm{m})\end{array}$ & $\begin{array}{c}\text { Comprimento } \\
(\mathrm{m})\end{array}$ & Declividade \\
\hline 1 & $-17,24$ & $-26,61$ & $-15,00$ & $-26,62$ & $4.023,7$ & $1: 429$ \\
\hline 2 & $-15,97$ & $-30,22$ & $-13,01$ & $-31,55$ & $6.041,3$ & $1: 423$ \\
\hline 3 & $-15,51$ & $-32,08$ & $-15,51$ & $-32,60$ & $6.044,2$ & $1: 364$ \\
\hline 4 & $-16,60$ & $-26,59$ & $-16,60$ & $-26,60$ & $4.297,7$ & $1: 430$ \\
\hline 5 & $-7,64$ & $-24,56$ & $-7,64$ & $-24,57$ & $4.105,5$ & $1: 242$ \\
\hline 6 & $-8,63$ & $-27,97$ & $-7,51$ & $-30,98$ & $5.224,1$ & $1: 270$ \\
\hline 7 & $-8,40$ & $-25,25$ & $-8,40$ & $-30,92$ & $5.573,6$ & $1: 330$ \\
\hline 8 & $-12,66$ & $-24,92$ & $-12,66$ & $-31,19$ & $5.594,1$ & $1: 456$ \\
\hline 9 & $-12,43$ & $-25,57$ & $-12,43$ & $-30,53$ & $5.798,0$ & $1: 441$ \\
\hline 10 & $-17,00$ & $-25,28$ & $-17,00$ & $-30,68$ & $4.621,8$ & $1: 558$ \\
\hline 11 & $-12,25$ & $-26,20$ & $-11,96$ & $-29,61$ & $5.101,6$ & $1: 365$ \\
\hline 12 & $-17,08$ & $-24,29$ & $-17,08$ & $-27,75$ & $5.853,5$ & $1: 811$ \\
\hline 13 & $-16,76$ & $-23,98$ & $-16,76$ & $-24,96$ & $5.562,7$ & $1: 770$ \\
\hline 14 & $-12,47$ & $-26,15$ & $-12,47$ & $-26,15$ & $6.139,5$ & $1: 448$ \\
\hline 15 & $-14,90$ & $-25,50$ & $-12,93$ & $-25,50$ & $5.862,7$ & $1: 553$ \\
\hline 16 & $-14,56$ & $-24,28$ & $-12,94$ & $-25,65$ & $6.180,1$ & $1: 635$ \\
\hline 17 & $-15,09$ & $-24,31$ & $-14,85$ & $-25,49$ & $5.853,0$ & $1: 634$ \\
\hline 18 & $-10,80$ & $-23,59$ & $-10,80$ & $-23,93$ & $6.198,1$ & $1: 484$ \\
\hline 19 & $-16,24$ & $-24,02$ & $-16,24$ & $-24,58$ & $5.539,1$ & $1: 711$ \\
\hline 20 & $-18,90$ & $-26,31$ & $-17,31$ & $-26,31$ & $5.582,8$ & $1: 753$ \\
\hline
\end{tabular}

aos arenitos de praia submersos que indicam condições pretéritas de estabilidade do nível do mar (Laborel, 1969; Santos, 1972; França, 1976; Dias et al., 1984; Hopley, 1986; Araújo \& Silva, 1996; Araújo \& Freire, 1997; Michelli et al., 2001; Caldas, 2002; Guerra \& Manso, 2004).

Quanto aos relevos negativos, estes foram registrados entre os perfis $6,8,9,10,11$ e $12 \mathrm{e}$, portanto configuram um canal com orientação norte-sul. A Tabela 3 reúne as dimensões do mesmo em relação a sua largura e profundidade máxima registradas em cada um dos perfis supracitados.

Os valores mínimo, máximo e médio de largura do canal são de 537,6, 2107 e $1486 \mathrm{~m}$, respectivamente, enquanto que a profundidade máxima do mesmo variou entre 4,5 e 9,5 m. A análise destes perfis indica um aumento na profundidade máxima do canal a partir do perfil 6 , atingindo seu 0 valor máximo de 9,3 m, no perfil 10 , a partir do qual as suas profundidades diminuem conforme as larguras aumentam (Fig. 6).

Em termos estruturais, a ocorrência deste canal na plataforma continental interna adjacente ao município de Tamandaré parece estar relacionada com falhas estruturais observadas na altura da foz do Rio Formoso e que apresentam direção concordante com a falha do Rio Formoso, localizada na área continental (Manso et al., 2003). Já em termos evolutivos, os relevos negativos estão associados à drenagem continental em períodos de níveis do mar mais baixos que 0 atual. Logo, esta feição foi considerada um paleocanal sem conexão evidente com o continente (Summerhayes et al., 1976; França, 1976; Ramsay, 1994) e provavelmente, representa a mesma feição descrita por Michelli et al. (2001), para uma região mais ao largo da área de estudo, onde as profundidades são superiores a $30 \mathrm{~m}$, em um trecho situado em profundidades superiores a $30 \mathrm{~m}$, no qual o mesmo passa a apresentar uma orientação NW-SE, 0 que sugere a presença de um meandro entre as profundidades de 25 e $30 \mathrm{~m}$. A sua preservação está relacionada ao caráter faminto da plataforma continental do Estado de Pernambuco, decorrente de um baixo índice de erosão continental e, portanto, de um pequeno aporte sedimentar e reduzidas taxas de sedimentação marinha.

\section{CONCLUSÃO}

A plataforma continental interna ao largo de Tamandaré apresentou relevos positivos, negativos e superfícies com declives mais suaves. Os relevos positivos se distribuem em torno das profun- 


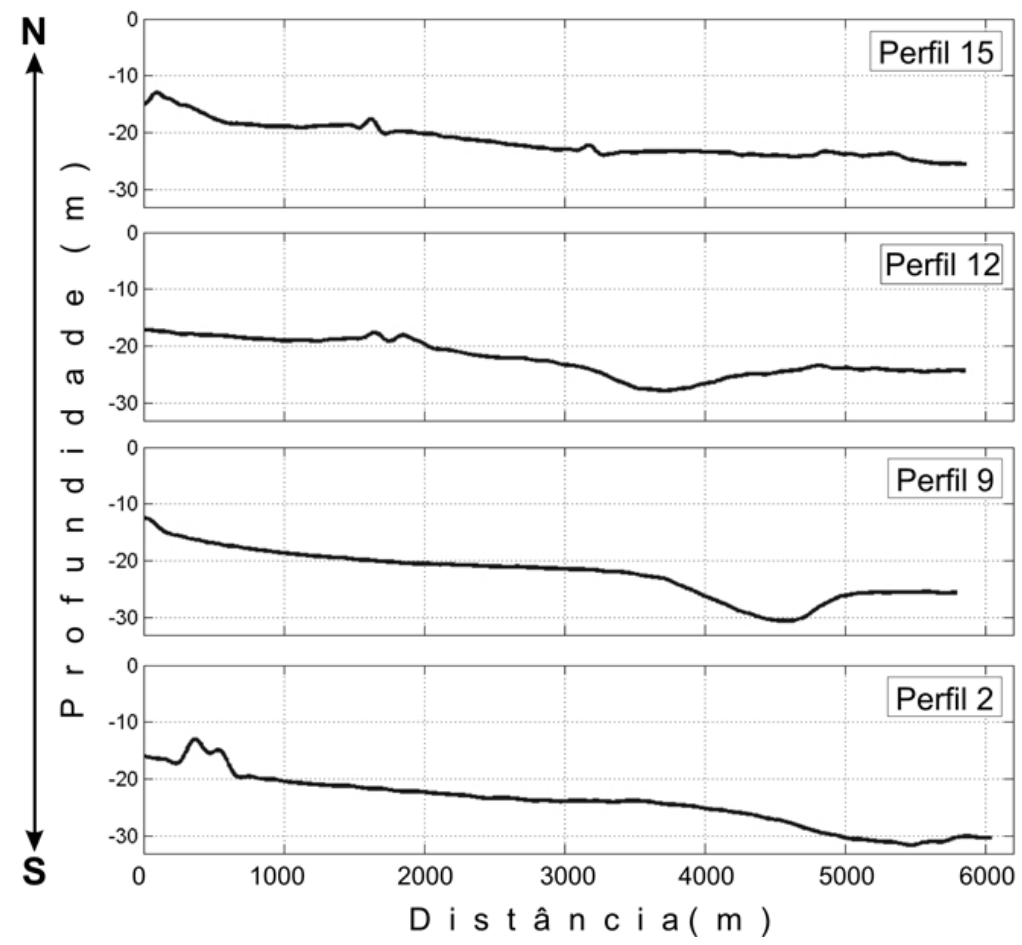

Figura 4 - Exemplos típicos de relevos positivos e negativos na plataforma continental interna adjacente ao município de Tamandaré.

didades de 16, 20 e $22 \mathrm{~m}$ e foram atribuídos à presença de linhas de arenitos de praia, traço morfológico característico do litoral pernambucano. Estas feições morfológicas têm suas formações relacionadas a períodos distintos, nos quais o nível do mar era mais baixo que 0 atual.

A ocorrência de arenitos de praia junto à isóbata de $20 \mathrm{~m}$ já foi reportada por outros autores para o Nordeste do Brasil, 0 que reforça a hipótese de que neste trecho da margem continental brasileira ocorreu uma estabilização do nível do mar nesta profundidade. Contudo, foi registrada pela primeira vez na plataforma continental interna ao largo de Tamandaré a ocorrência de outras duas profundidades de provável estabilização do nível do mar: 16 e $22 \mathrm{~m}$.

Como citado anteriormente, a localização e identificação destas linhas de arenito de praia submersos através de amostragem direta são fundamentais para a elaboração de curvas de variação do nível do mar, numa escala regional. Através de métodos geocronológicos, a idade de formação dos arenitos de praia poderá ser determinada e, comparando-se as idades de linhas consecutivas e geralmente paralelas, se obterá um cenário das flutuações do nível do mar em termos espaço-temporais.

Ademais, a localização dos arenitos de praia submersos representa uma importante contribuição ao Programa de Monito- ramento dos Recifes de Coral do Brasil (Reef Check Brasil). A qualidade ambiental destes ecossistemas poderá ser avaliada a partir de censos visuais de indicadores, como peixes, invertebrados e tipos de substrato. Os resultados deste monitoramento deverão alimentar a rede nacional de monitoramento de recifes de coral, vinculada ao Reef Check, o maior programa internacional de monitoramento de recifes de coral, presente em mais de 40 países e desenvolvido a partir da Rede Global de Monitoramento de Recifes de Coral (GCRMN) das Nações Unidas.

Claramente registrados nos perfis batimétricos, os relevos negativos são correlatos a um paleocanal sem uma clara conexão com o continente e que apresentou uma orientação N-S, profundidade máxima e largura média de 9,5 e $1486 \mathrm{~m}$, respectivamente. 0 tamanho da malha amostral usada no trabalho permitiu obter mais detalhes da porção do paleocanal localizada próximo ao continente, que sugerem que o Rio Formoso já cruzou a plataforma continental interna ao largo de Tamandaré.

De forma geral, a descrição das feições topográficas aqui apresentadas fornece subsídios para pesquisas acerca da evolução costeira na plataforma continental sul do Estado de Pernambuco, visto que essas feições indicam condições de níveis do mar mais baixos que 0 atual. Além disto, contribui para o programa de monitoramento nacional e global de recifes de coral, 
Tabela 2 - Altura e largura dos relevos positivos nas profundidades de 16, 20 e 22 metros, em cada um dos perfis batimétricos levantados.

\begin{tabular}{|c|c|c|c|c|c|}
\hline \multirow{2}{*}{ Perfil } & $16 \mathrm{~m}$ & \multicolumn{2}{|c|}{$20 \mathrm{~m}$} & \multicolumn{2}{c|}{$22 \mathrm{~m}$} \\
\cline { 2 - 6 } & Altura $(\mathrm{m})$ & Altura $(\mathrm{m})$ & Largura $(\mathrm{m})$ & Altura $(\mathrm{m})$ & Largura $(\mathrm{m})$ \\
\hline 1 & - & 5 & 169,3 & - & - \\
\hline 2 & - & 5,4 & 445,3 & - & - \\
\hline 3 & - & 3,3 & 326,1 & - & - \\
\hline 4 & - & 3,4 & 520,1 & - & - \\
\hline 5 & 9 & - & - & - & - \\
\hline 6 & 9,8 & - & - & - & - \\
\hline 7 & - & 9,5 & - & - & - \\
\hline 8 & 4,3 & - & - & - & - \\
\hline 9 & - & - & - & - & - \\
\hline 10 & - & - & - & - & - \\
\hline 11 & 4 & 2 & 715 & - & - \\
\hline 12 & - & 2,9 & 500 & - & - \\
\hline 13 & - & 2,7 & 810 & - & - \\
\hline 14 & 4 & 0,5 & 389 & 1,6 & 333 \\
\hline 15 & 5,2 & 2,7 & 537,7 & 1,5 & 177,4 \\
\hline 16 & 2,7 & - & - & - & - \\
\hline 17 & 2,3 & 1,6 & 495 & - & - \\
\hline 18 & 4,2 & 5,1 & 561 & 2,3 & 426,6 \\
\hline 19 & - & 2,6 & 253 & 3,2 & 419,4 \\
\hline 20 & - & 3,6 & 530 & - & - \\
\hline & & & & & \\
\hline
\end{tabular}

Tabela 3 - Profundidades máximas e larguras do canal registrado nos perfis batimétricos levantados.

\begin{tabular}{|c|c|c|}
\hline Perfil & $\begin{array}{c}\text { Profundidade } \\
\text { máxima }(\mathrm{m})\end{array}$ & $\begin{array}{c}\text { Largura } \\
(\mathrm{m})\end{array}$ \\
\hline 1 & - & - \\
\hline 2 & - & - \\
\hline 3 & - & - \\
\hline 4 & - & - \\
\hline 5 & - & - \\
\hline 6 & $-4,5$ & 537,6 \\
\hline 7 & - & - \\
\hline 8 & $-6,9$ & $1.306,5$ \\
\hline 9 & $-7,5$ & 1.355 \\
\hline 10 & $-9,5$ & 1.868 \\
\hline 11 & $-7,6$ & 1.742 \\
\hline 12 & $-5,7$ & 2.107 \\
\hline 13 & - & - \\
\hline 14 & - & - \\
\hline 15 & - & - \\
\hline 16 & - & - \\
\hline 17 & - & - \\
\hline 18 & - & - \\
\hline 19 & - & - \\
\hline 20 & - & - \\
\hline & & \\
\hline
\end{tabular}

já que disponibiliza para a comunidade científica a localização de ambientes importantes devido à sua biodiversidade e também por sustentarem recursos pesqueiros explorados pela pesca artesanal na região.

\section{REFERÊNCIAS}

ARAÚJO TCM \& FREIRE GSS. 1997. Evidências de variação do nível do mar na plataforma continental do estado do Ceará. Anais VII Congr. Latino-americano sobre Ciências do Mar, 47-48, Santos, SP.

ARAÚJO TCM \& SILVA CG. 1996. Análise sismoestratigráfica da plataforma continental rasa entre Cabo Frio e Cabo de São Tomé - RJ. Anais XXXIX Congr. Bras. Geol., 466-468, Salvador, BA.

BRANNER J. 1904. Os recifes pétreos do Brasil, sua relação geológica e geográfica, com um capítulo sobre os recifes de coral. Bull. Mus. Comp. Zool., Cambridge, 44(7): 1-285.

CALDAS LH de 0. 2002. Late quaternary coastal evolution of the northern Rio Grande do Norte coast, NE Brazil. PhD Thesis, Kiel, ChristianAlbrechts Universität zu Kiel, 100 pp.

CESAR FB \& PADOVANI BF. 2004. Avaliação da metodologia Reef Check para a ictiofauna de ambiente recifal protegido, na APA Costa dos Corais, Tamandaré/PE. Anais I Congr. Bras. de Oceanografia e XVI Semana Nacional de Oceanografia, p. 804, Itajaí, SC.

DIAS GTM, GORINI MA, GALLEA CG, ESPINDOLA CRS, MELLO SL, DELLAPIAZA H \& CASTRO JRJC. 1984. Bancos de arenitos de praia (beach-rocks) submersos na plataforma continental SE brasileira. Anais XXXII Congr. Bras. Geol., 1540-1546, Salvador, BA.

DHN. DIRETORIA DE HIDROGRAFIA E NAVEGAÇÃO. 2004. Tábua das Marés para o Porto de Suape (Estado de Pernambuco). Disponível em: $<$ http://www.dhn.mar.mil.br> Acesso em: 7 jan. 2005.

FRANÇA AMC. 1976. Sedimentos superficiais da margem continental nordeste brasileira. Rev. Bras. Geociências, 6 (2): 71-88.

GUERRA NC \& MANSO VAV. 2004. Beachrocks (Recifes de Arenito). In: ESKINAZI-LEÇA E, NEUMANN-LEITÃO $S$ \& COSTA MF (Org.). Oceanografia: Um Cenário Tropical. Recife: Ed. Bagaço, p. 109-130.

HOPLEY D. 1986. Beach-rocks as sea-level indicator. In: VAN DE PLASSCHE 0 (Ed.). Sea-level research: a manual for the collection and evaluation data. GeoBooks, Norwich U.K., 157-173.

LABOREL J. 1969. Les Peuplements de Madréporaires de Côtes Tropicales du Brésil. Univ. d’Abidjan, Série E, II Fasc. 3, 260 pp.

LIMA DCC. 2003. Aplicação de imagem do satélite LandSat TM5 e de 


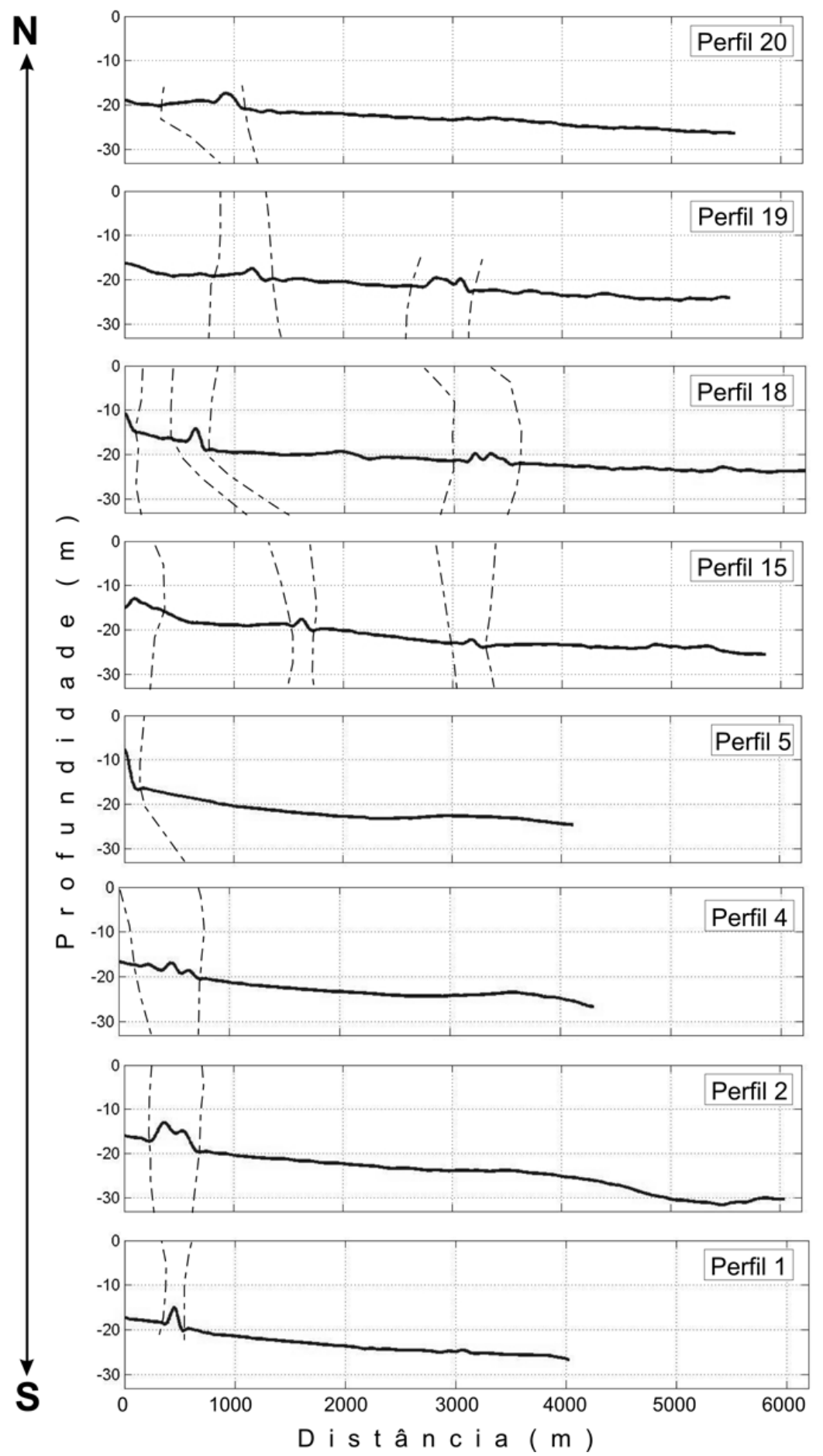

Figura 5 - Linhas tracejadas indicando a ocorrência de relevos positivos em torno das profundidades de 16 , 20 e 22 metros, nos perfis batimétricos 1, 2, 4, 5, 15, 18, 19 e 20. 


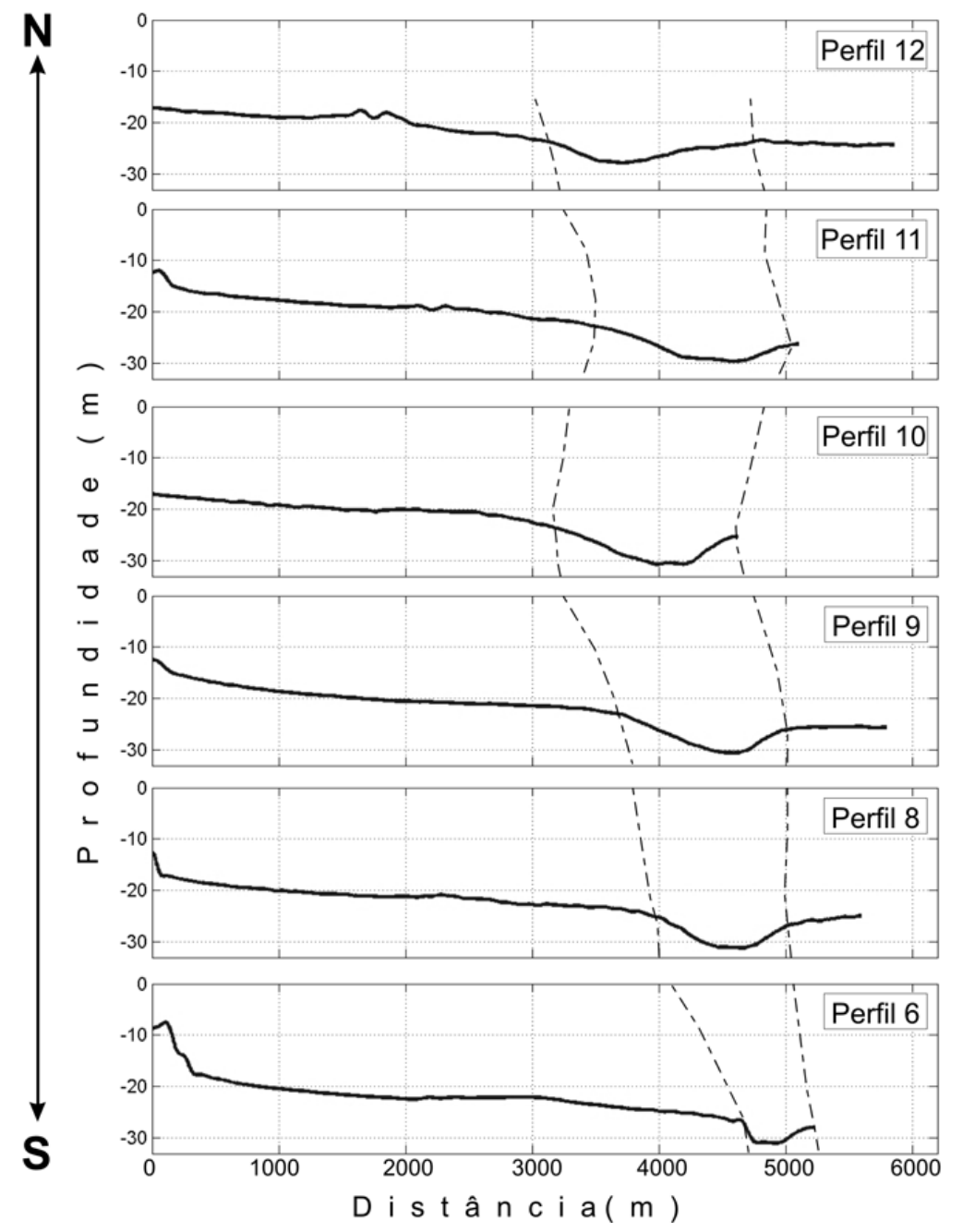

Figura 6 - Linhas tracejadas indicando a ocorrência de um canal nos perfis batimétricos 6, 8, 9, 10, 11 e 12.

fotografias aéreas verticais para o mapeamento dos recifes costeiros e análise dos processos físicos litorâneos relacionados - Tamandaré, PE, Brasil. Recife, Universidade Federal de Pernambuco, Dissertação de Mestrado, $120 \mathrm{pp}$.

LIMEBURNER R (Ed.). 1985. CODE-2: Moored array and large-scale data report, WHOI Tech. Rep. 85-35, CODE Tech. Rep. 38, Woods Hole Oceanogr. Inst., Woods Hole, Mass. 220 pp.

MABESOONE JM. 1964. Origin and age of the sandstone reefs of Pernambuco (Northeastern Brazil). J. Sediment. Petrology, 34: 715-726.

MAIDA M \& FERREIRA BP. 1997. Coral Reefs of Brazil: an overview. Panama, International Coral Reef Symposium, 8, Proc. 1: 263-274.

MANSO VAV, CORRÊA ICS \& GUERRA NC. 2003. Morfologia e Sedimentologia da Plataforma Continental Interna entre as Praias Porto de Galinhas e Campos - Litoral Sul de Pernambuco, Brasil. Rev. Pesq. Geociências, 30(2): 17-25.
MICHELLI M, ARAÚJO TCM, MAIDA M \& VITAL H. 2001. Indicatives of ancient conditions of sea level stability on the southern Pernambuco continental shelf. Rev. Pesq. Geociências, 28(2): 25-33.

RAMSAY PJ. 1994. Marine geology of the Sodwana Bay shelf, southeast Africa. Mar. Geol., 120: 225-247.

SANTOS MECM. 1972. Paleografia do Quaternário Superior na plataforma continental norte brasileira. Anais XXVI Congr. Bras. Geol., 267288, Belém, PA.

SUMMERHAYES CP, FAINSTEIN R \& ELLIS JP. 1976. Continental margin off Sergipe and Alagoas, Northeast Brazil: a reconnaissance geophysical study of morphology and structure. Mar. Geol., 20: 345-361.

VORA KH \& ALMEIDA F. 1990. Submerged reef systems on the central western continental shelf of India. Mar. Geol., 91: 255-262. 


\section{NOTAS SOBRE OS AUTORES}

João Marcello Ribeiro de Camargo. Graduado em Oceanografia (UERJ/2002), Especialista em Gestão de Ambientes Costeiros Tropicais (UFPE/2003), e Mestre em Oceanografia Geológica (UFPE/2005). Atua nas áreas de Oceanografia Geológica; Geofísica; Monitoramento e manejo de ecossistemas marinhos e costeiros.

Tereza Cristina Medeiro de Araújo. Graduada em Geologia (UFRN-1985), Mestre em Geofísica (UFPA-1989) e Doutora em Geofísica (UK-1994). Professora Adjunta do Departamento de Oceanografia da Universidade Federal de Pernambuco. Atua nas áreas de Geologia e Geofísica da Margem Continental Brasileira; Evolução da linha de costa; Sedimentologia marinha.

Mauro Maida. Graduado em Oceanologia (FURG-1987), Mestre (JCUNQ-1990) em Ecologia Marinha e Doutor em Ecologia Marinha (JCUNQ-1993). Professor Adjunto do Departamento de Oceanografia da Universidade Federal de Pernambuco. Coordenador do Projeto Recifes Costeiros (UFPE-IBAMA-FMA-BID-AVINA). Atua nas áreas de Ecologia e dinâmica de recifes de coral e outros ecossistemas marinhos; impacto, recuperação e preservação ambiental; monitoramento e manejo de ecossistemas marinhos e costeiros.

Thales Mitsuro Ushizima. Graduado em Ecologia (UNESP/2002) e Mestre em Geociências e Meio Ambiente (UNESP/2005). Atua nas áreas de Geoprocessamento, Mergulho Científico e Monitoramento dos Recifes de Coral do Brasil. 